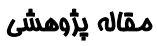

\section{ويز كى هاى جمعيتى، اقتصادى و اجتماعى معتادين به مواد مخدر مراجعه كننده به مراكز ترك اعتياد خراسان شمالى}

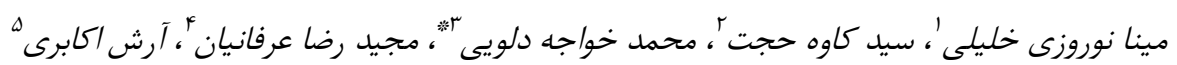

'دستيار تخصصى يزشكى اجتماعى، دانشگاه علوم يزشكى مشهد، گروه يزشكى اجتماعى، عضو مركز تحقيقات اعتياد و علوم رفتارى دانشكاه علوم يزشكى خراسان شمالى، مشهد، ايران.

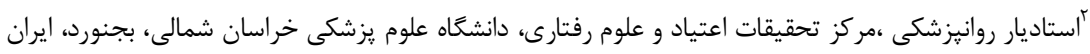

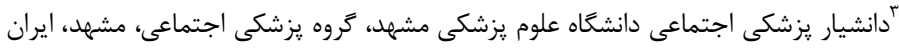

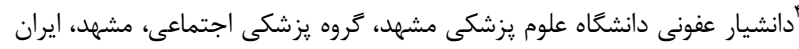

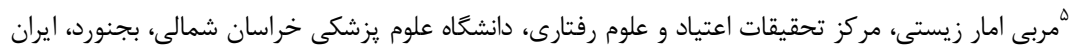

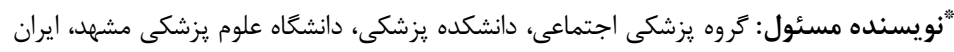

يست الكترونيك: KhajedalueeM@mums.ac.ir

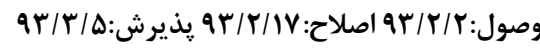

جكيده زمينه و هدف: اعتياد به مواد مخدر يكى از جهار بحران تهديد كننده بشر در كنار بحران هاى زيست محيطى، هسته ایى و جمعيتى است.

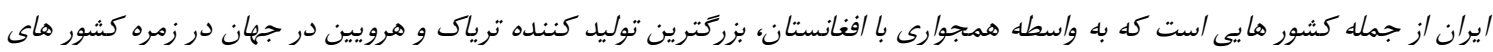

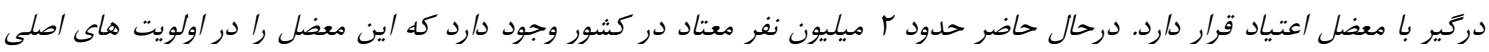
بهد/شتى و اجتماعى قرار داده است.

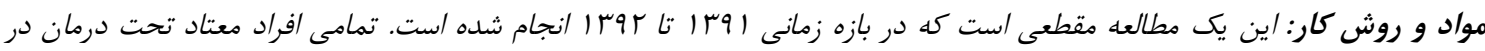

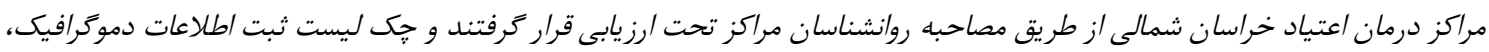

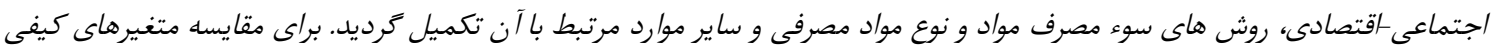

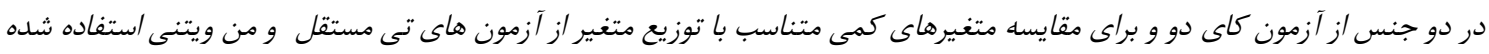

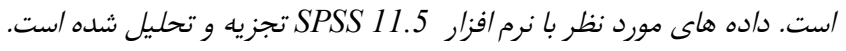

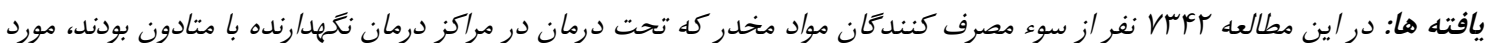

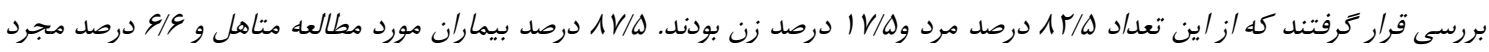

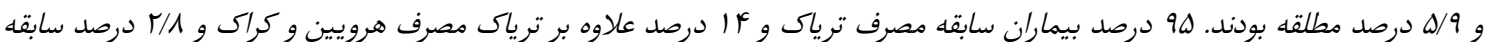
مصرف شيشه داشتند.

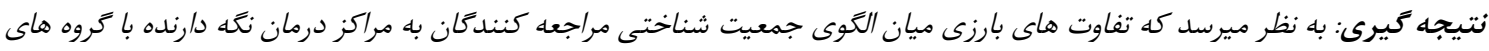

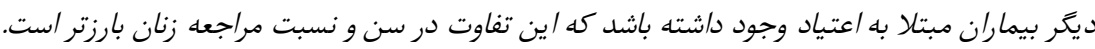

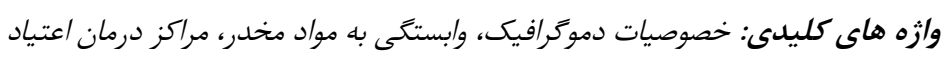

است و متاسفانه جهارمين تجارت ڤيرسود يس از نفت، مقدمه

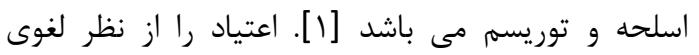

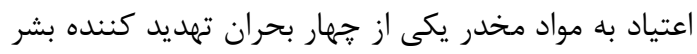
عادت كردن و خو گرفتن تعريف شده است. ولى به طور

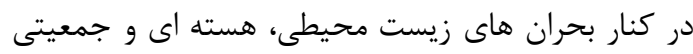


اغلب بر اساس ويزگى ها و نياز هاى مردان شكل كرفته است. اين درحاليست كه تحقيقات نشان مى دهد كه

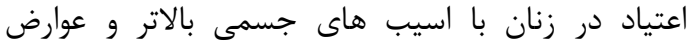

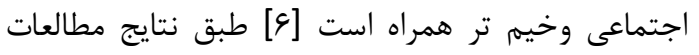
اخير صورت كَفته در كشور تغييراتى در الكَى سوء

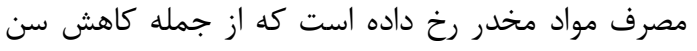

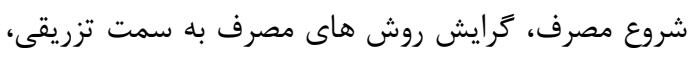

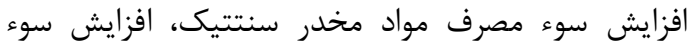

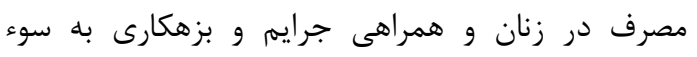

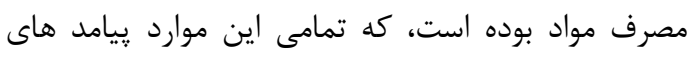

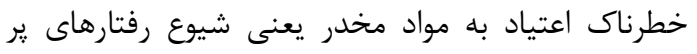

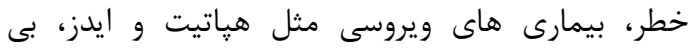

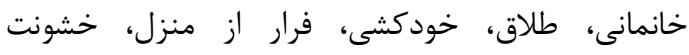

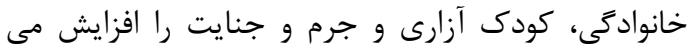

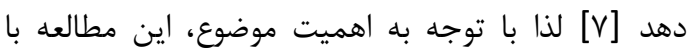

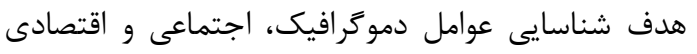

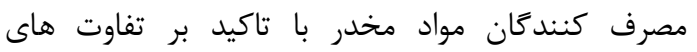
جنسيتى در استان خراسان شمالى در فاصله زمانى نيمه

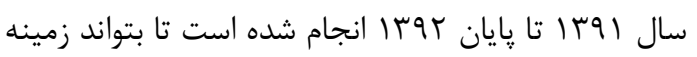
اي براى مداخله در عوامل اجتناب يذير باشد.

\section{روش كار}

اين يك مطالعه مقطعى است كه در بازه زمانى اجوبا تا

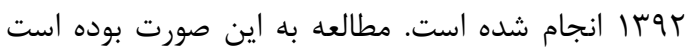

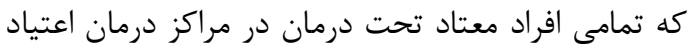

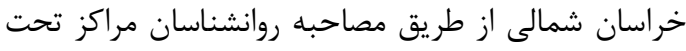

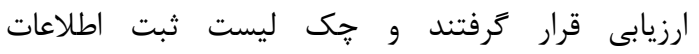

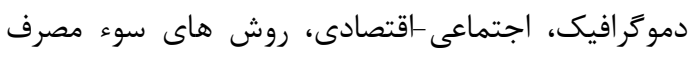
مواد و نوع مواد مصرفى و ساير موارد مرتبط با با آن تكميل

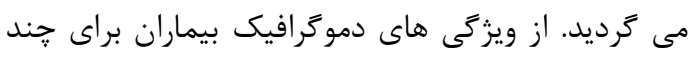

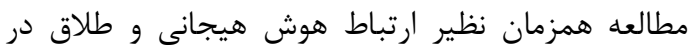

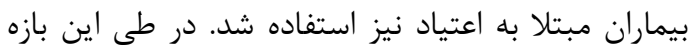

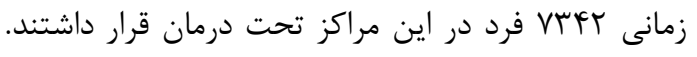

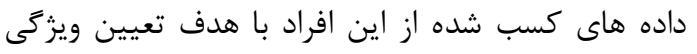

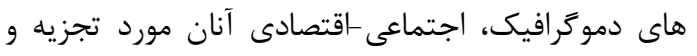
تحليل قرار كرفت. داده هاى مورد نظر با نرم افزار 11.5 تجزيه و تحليل شده است. براى توصيف داده داده ها از ماز

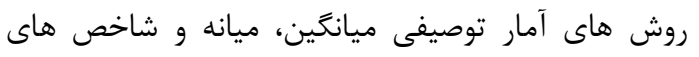

متعارف، اعتياد براى شناسايى رفتارهاى خود مخربى به

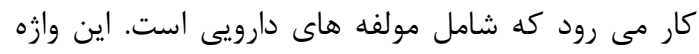

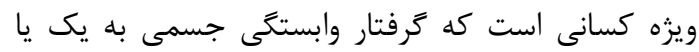
بيش از يك داروى غير قانونى هستند [1]

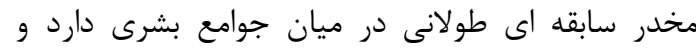

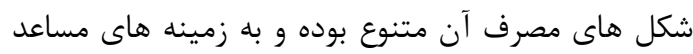

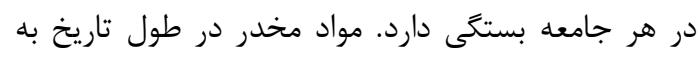

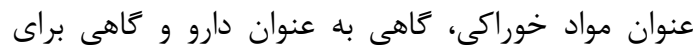

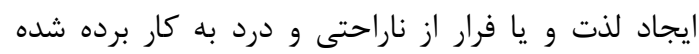

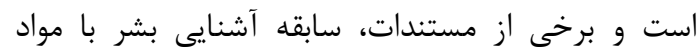

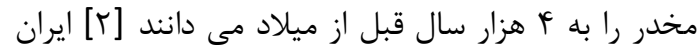

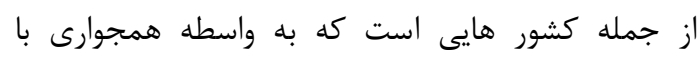

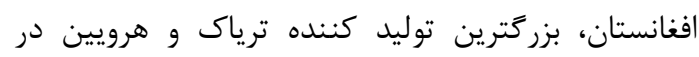
جهان در زمره كشور هاى در كير با معضل اعتياد قرار دارد.

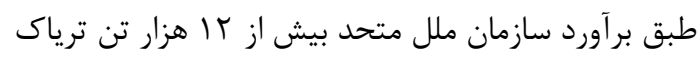

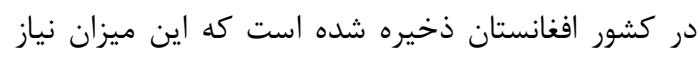

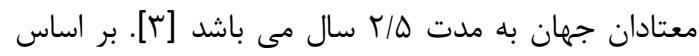

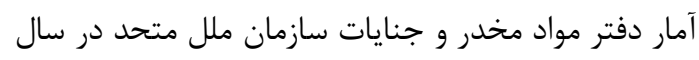

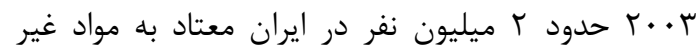
قانونى شامل مواد افيونى، حشيش و مون مواد محرى برى بوده اند.

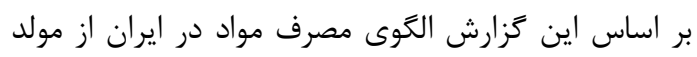

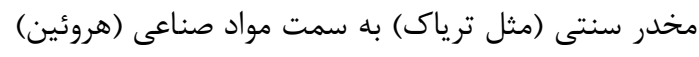

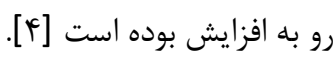
طبق نتايج קند مطالعه كشورى كه با همكارى دفتر

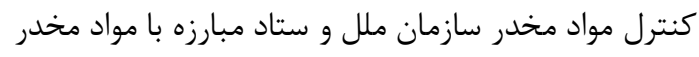

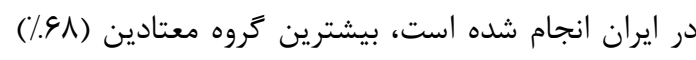

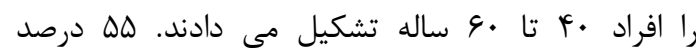

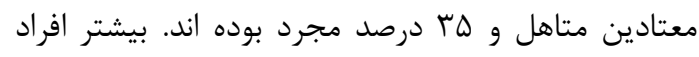

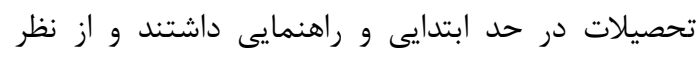

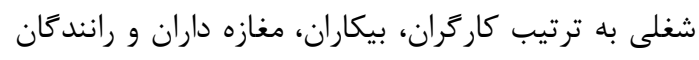

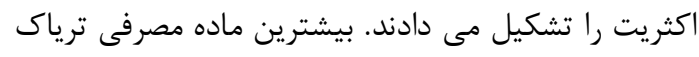

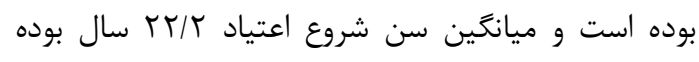

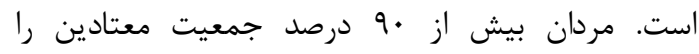
تشكيل مى دادند [0]

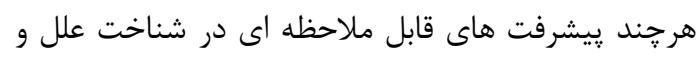

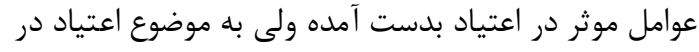

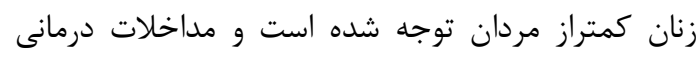


ولى در كروه زنان MN/V درصد خانه دار هستند كه اين

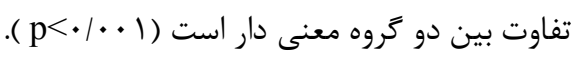

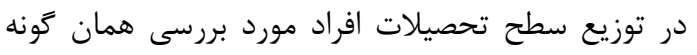

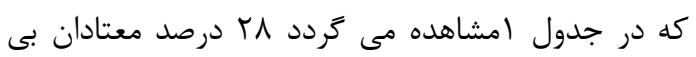

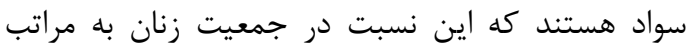

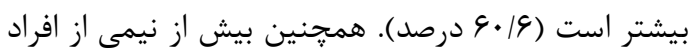
مورد بررسى تحصيلات كمتر از متوسطه دارند (ع) (عاعها

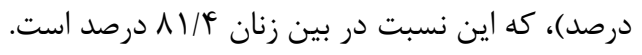

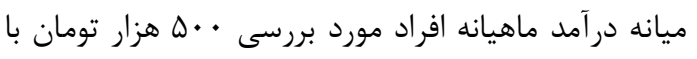

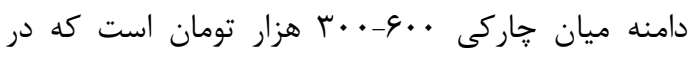

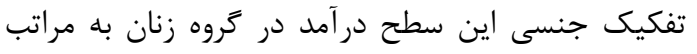

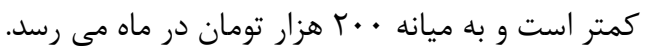

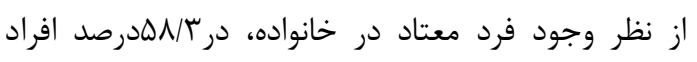

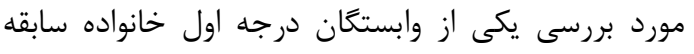

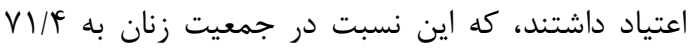

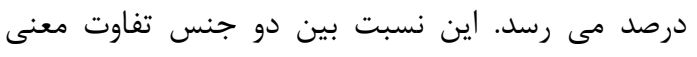

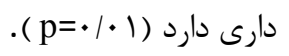

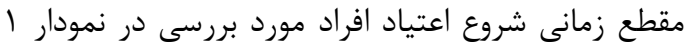

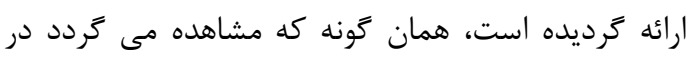

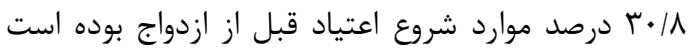

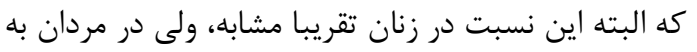

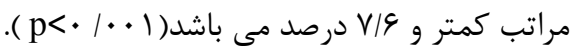

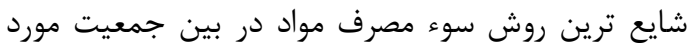

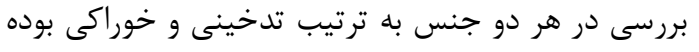

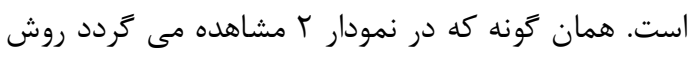

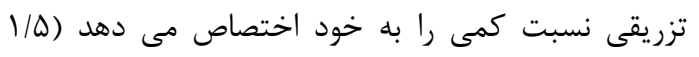

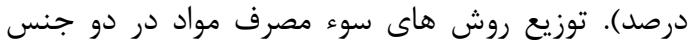

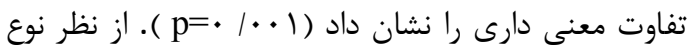

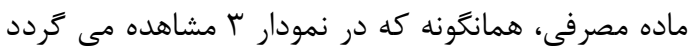

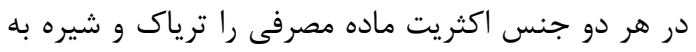
خود اختصاص مى دهد. در دين بين مواد مخدر ماده صناعى اين

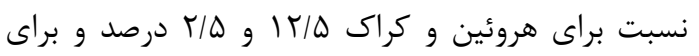

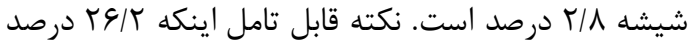

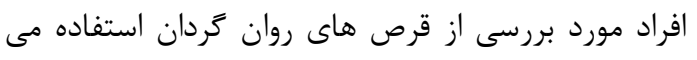

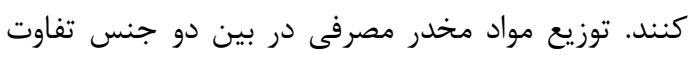

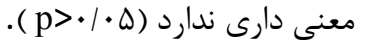

يراكندگى مناسب با توزيع متغير استفاده شده است. براى

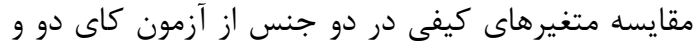

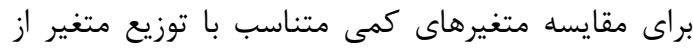

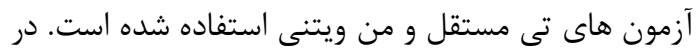

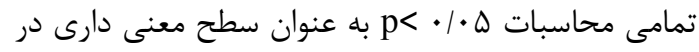

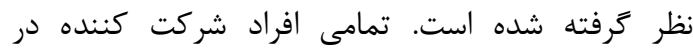

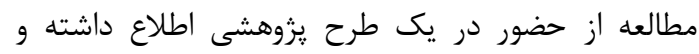

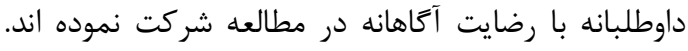

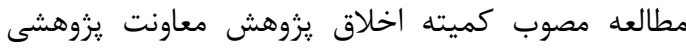

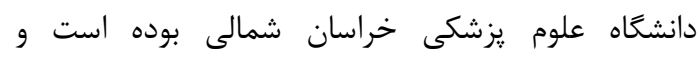
يزوهشكَران هيج كونه تعارض منافعى در طى مطالعه

نداشته اند.

يافته ها

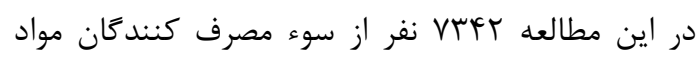
مخدر كه به مراكز درمان نتخهدارنده با متادون مراجعه

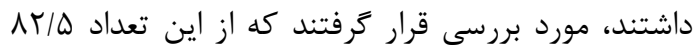

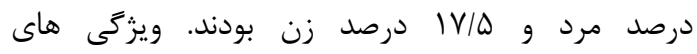

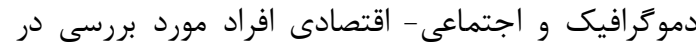

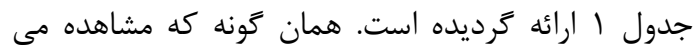

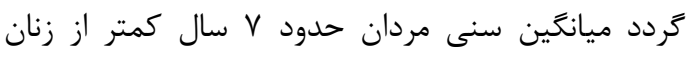

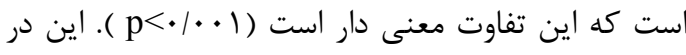

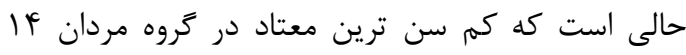

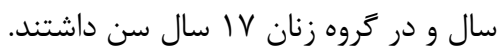

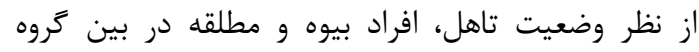

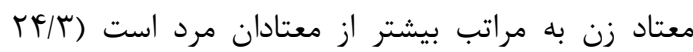

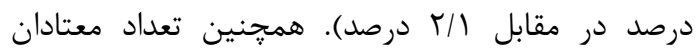

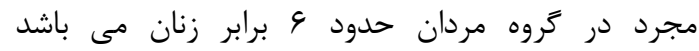
(V/V)

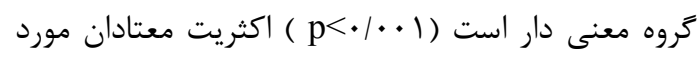

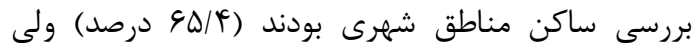

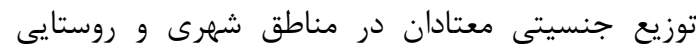

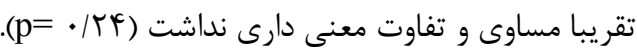

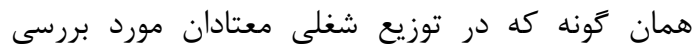

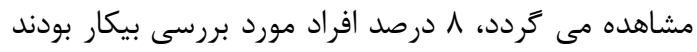

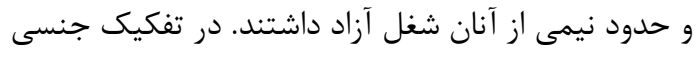

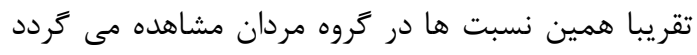




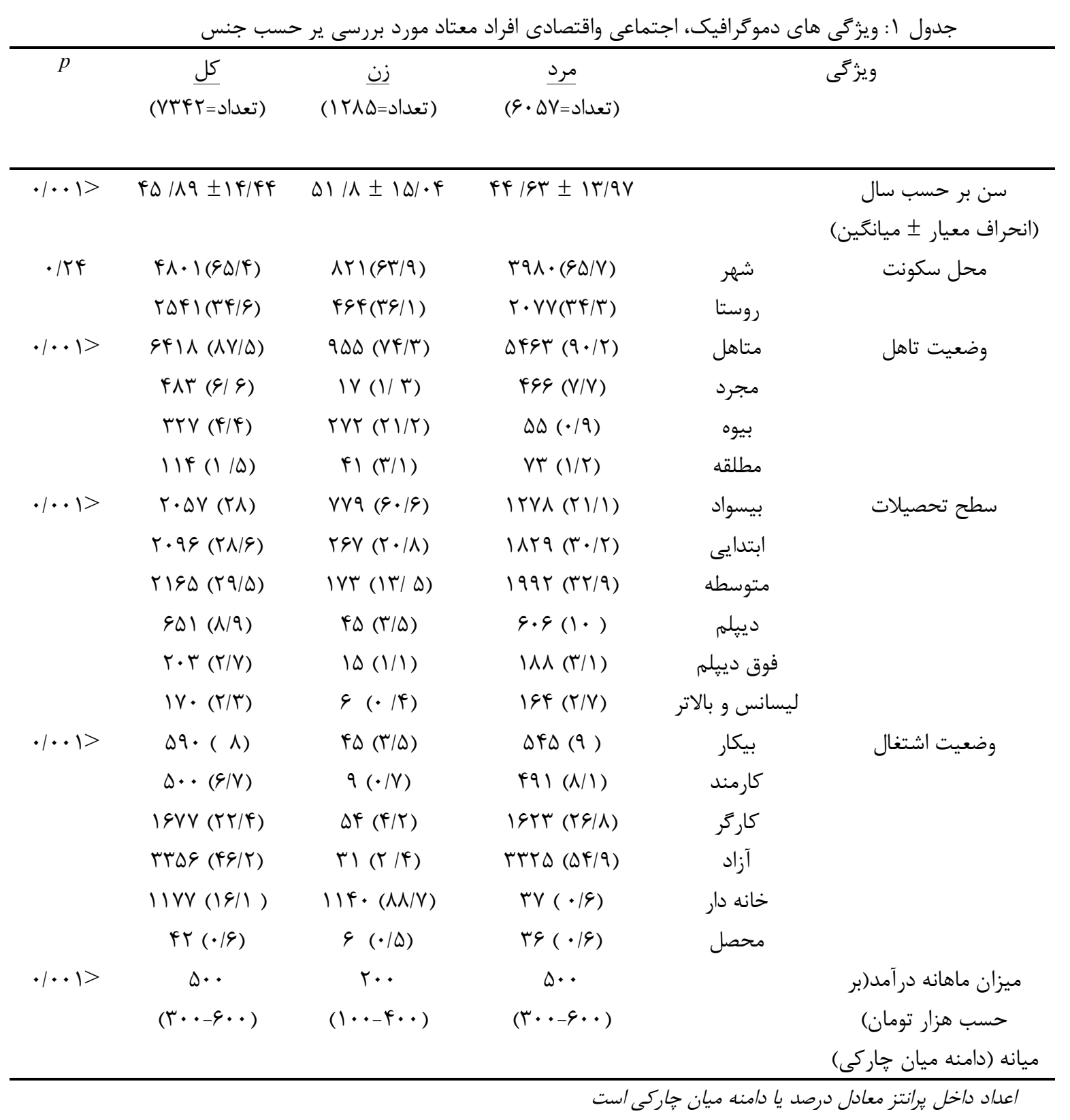




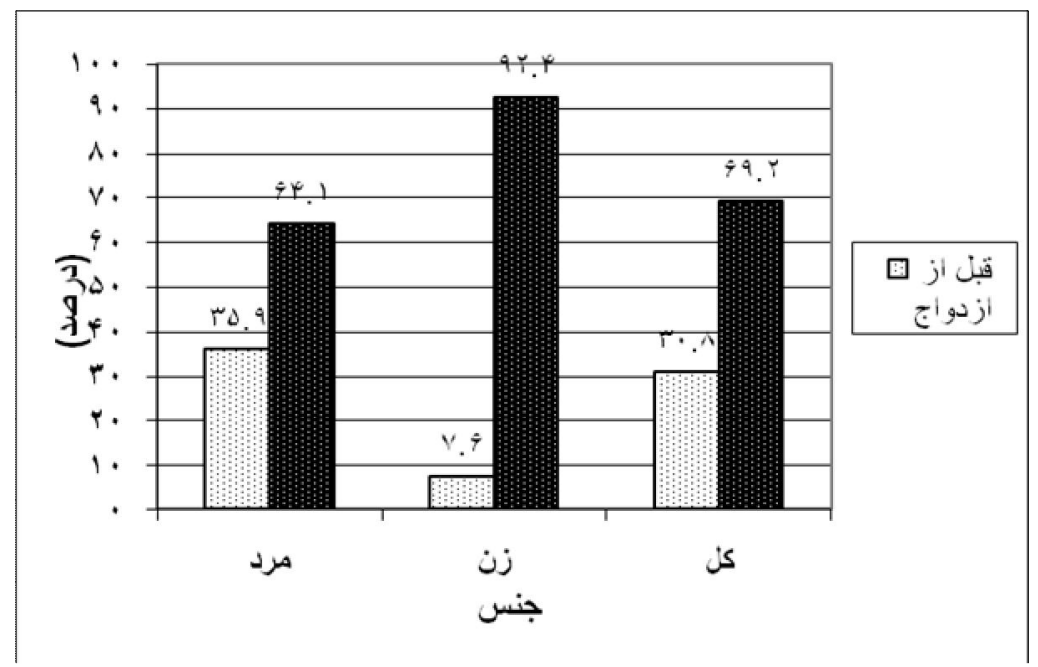

نمودار ا: توزيع فراوانى زمان ابتلا به اعتياد بر حسب جنس در افراد مورد بررسى

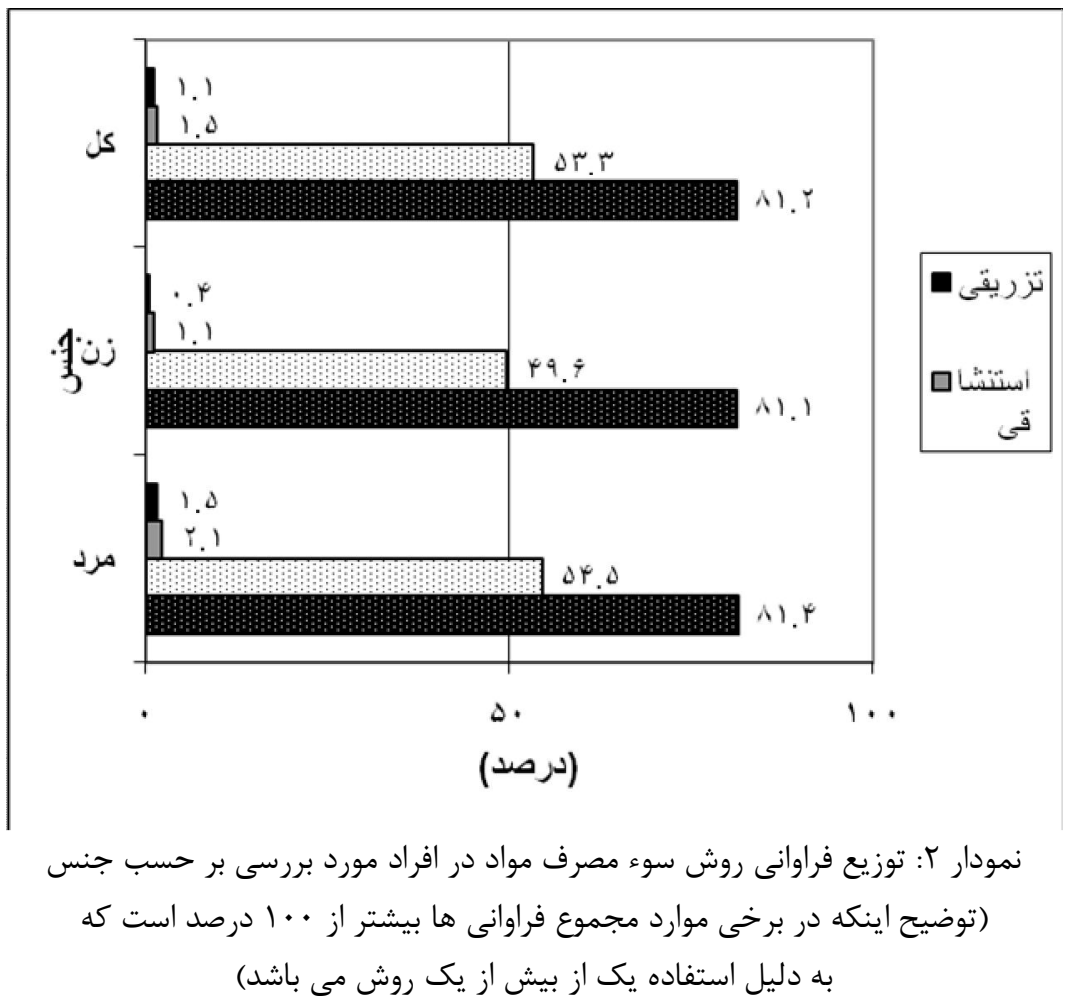




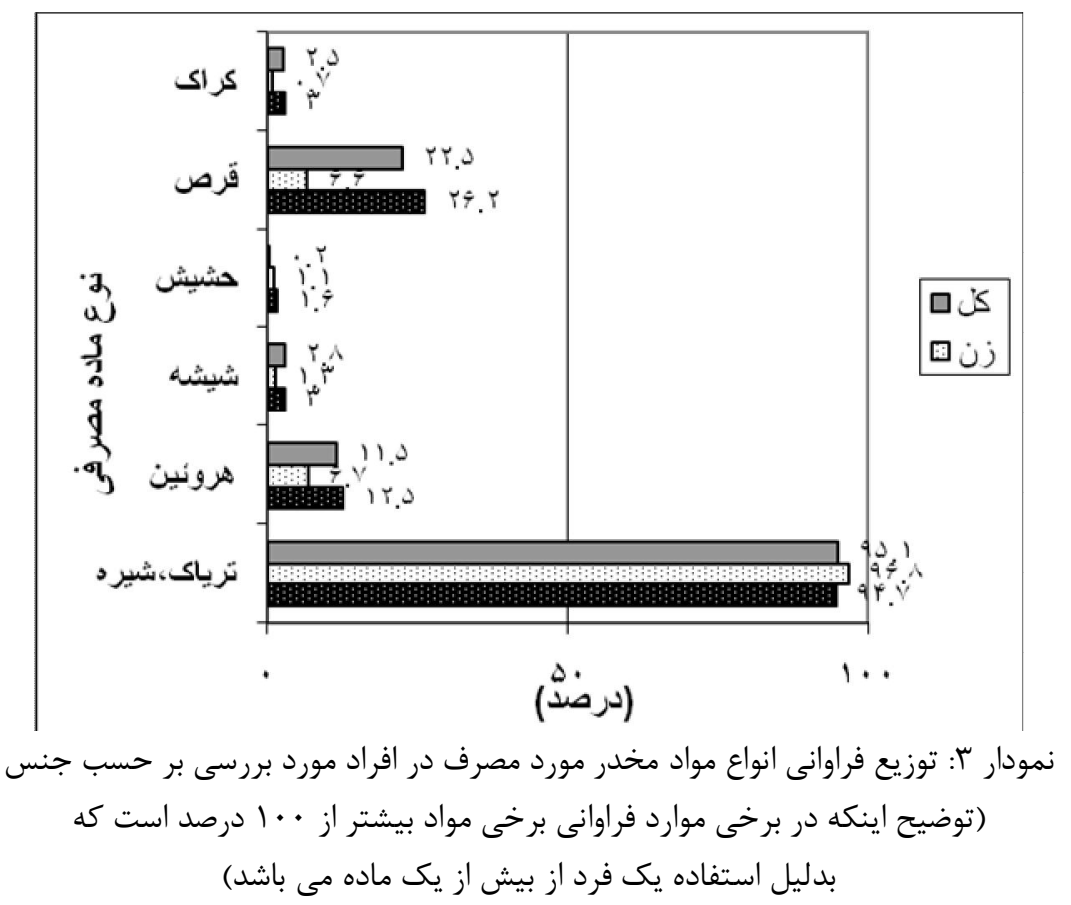

بايستى دو نكته در نظر داشت اول اينكه مطالعات ما بحث

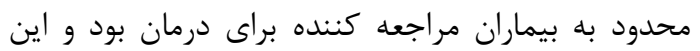
نتايج اين مطالعه نشان داد كه در يك بازده زمانى حدود

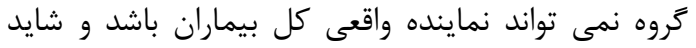

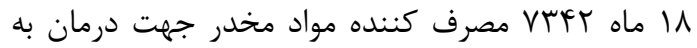

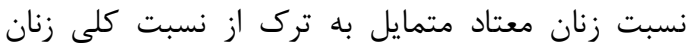

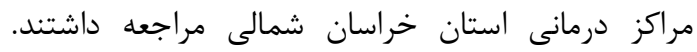
معتاد بيشتر باشد. نكته دوم اينكه از آخرين مطالعه كشورى جند سالى مى كذرد و با توجه به روند افزايش نسبت زنان معتاد در كشور، تا حدودى افزايش نسبت زنان

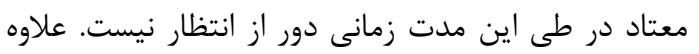
بر اين كم شدن فشارها و محدوديت هاى اجتماعى براى

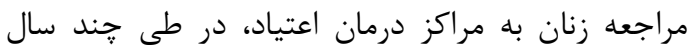

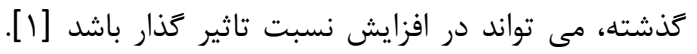

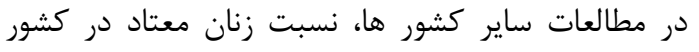

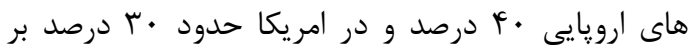

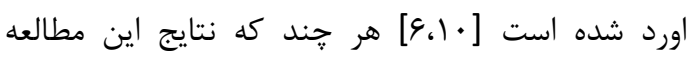

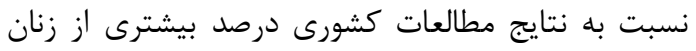

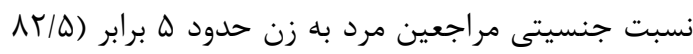

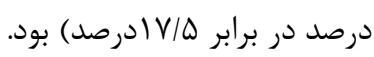
رحيمى موقر و همكاران در بررسى سيستماتيك مطالعات

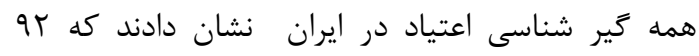

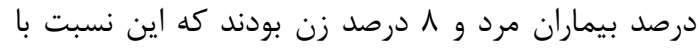

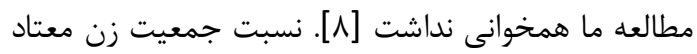

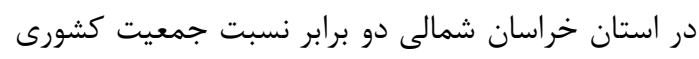

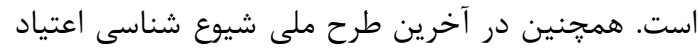

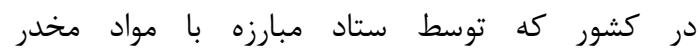

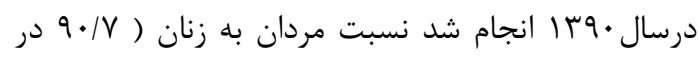

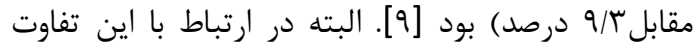


درصد بود. رحيمى موقر در آخرين ارزيابى كشورى ميزان

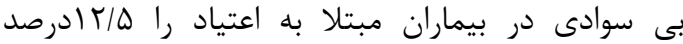
كزارش نمود كه با مطالعه ما همخوانى نداشت [ـ]. بايد

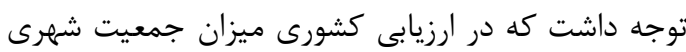

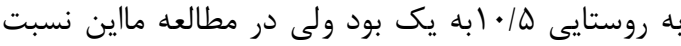
حدود دو به يك مى باشد. نسبت بالاى جمعيت روستايى

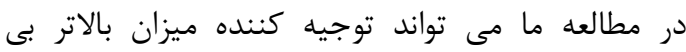
سوادى در مطالعه ما باشد. در بررسى وضعيت تاهل نتايج نشان داد كه NV/D درصد

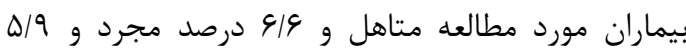
درصد مطلقه و بيوه بودند. در مطالعه عباسى و همكاران

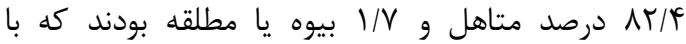

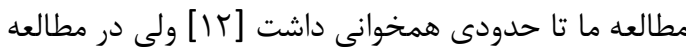
كشورى رحيمى موقر و همكاران هاعها درصد متاهل بودند

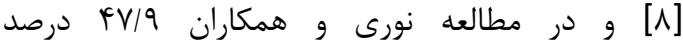

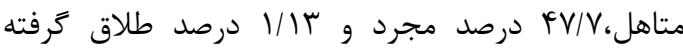
بودند كه با مطالعه ما متفاوت است [9] البته در مطالعه نورى فقط بيماران مصرف كننده مواد محرك در شهر

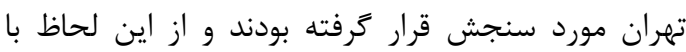
بيماران مطالعه ما اختلاف داشتند. در مطالعه ما ميزان زنان طلاق كرفته يا بيوه بطور معنا دارى بيشتر از مردان

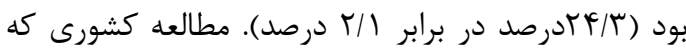
ميزان طلاق در مردان و زنان مبتلا به اعتياد را مورد

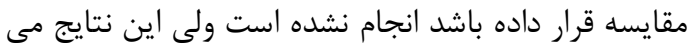
تواند نشان دهنده مراجعه كمتر مردان مجرد و يا طلاق كرفته براى درمان نسبت به زنان باشد و اين نسبت هان هان إندان ممكن است قابل تعميم به جمعيت عمومى معتادان نباشد.

نتايج مطالعه ما نشان داد كه هو درصد بيماران سابقه

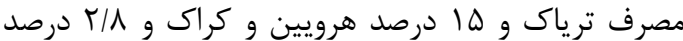
سابقه مصرف شيشه داشتند. البته بايد توجه داشت كه كر كراك بدليل مصرف همزمان حند دارو اين ميزان بالاتر از صد شده است. در مطالعه حاجى رسولى بر روى مراجعه

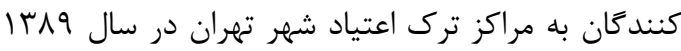
ميزان مصرف ترياك و شيره

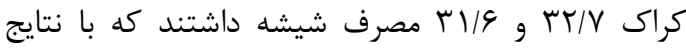

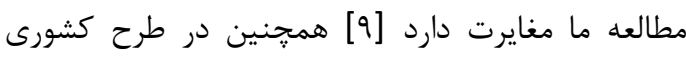

معتاد را نشان مى دهد ولى اين نسبت هنوز تا نسبت هاى كشور هاى ارويايى وامريكايى فاصله دارد. مطالعه ما نشان داد كه ميانكَين سنى بيماران حدود هان سال بود. رحيمى موقر و همكاران در مطالعه كشورى مئن شيوع اعتياد در كشور ميانگين سنى بيماران مورد مطالعه

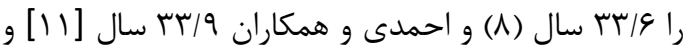

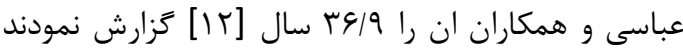
كه با مطالعه ما مغايرت داشت. البته بايد توجه داشت داشت كه كه

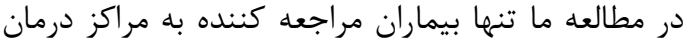

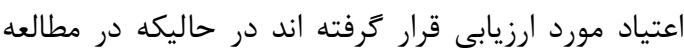
كشورى ارزيابى سريع اعتياد توسط موقر و همكاران، بيماران از طريق مراجعه به منزل مورد سنجش قرار كرئ سرفته اند و منحصر به كروه مراجعه كننده براى درمانه درمان نبوده است. در مطالعه عباسى و همكاران در استان كلستان نيز اطلاعات يرونده هاى بيماران مراجعه كننده به يك مركز دولتى درمان بصورت كذشته نكر مورد بررسى قرار ترفتها

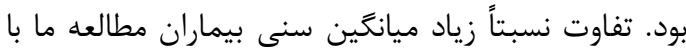

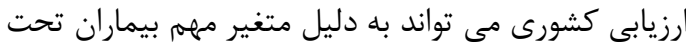

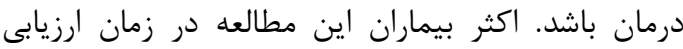

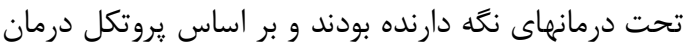

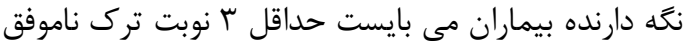
در سابقه انها وجود داشته باشد تا مجوز ورود به درمانهاى نكَه دارنده را داشته باشند و بالاتر بودن ميانكَين سنى بيماران نسبت به مطالعات ديخر در كشور مى تواند به اين

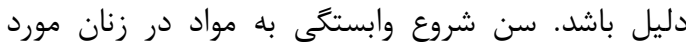

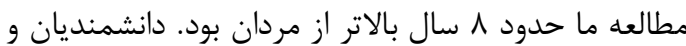
همكاران سن شروع اعتياد در ايران را در زنان بطور

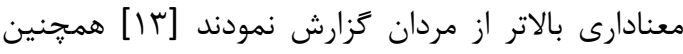
رحيمى موقر و همكاران در يك مطالعه سيستماتيك بر آران روى الكوى اعتياد در زنان ايرانى سن شروع اعتياد در زنان

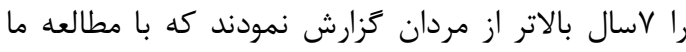

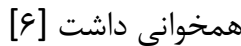
نتايج مطالعه ما در حوزه تفاوت هاى تحصيلات نشان دان داد

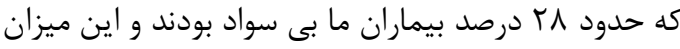

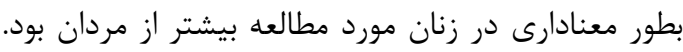
همجنين بيش از نيمى از بيماران مورد مطالعه تحصيلات

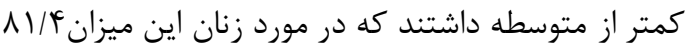


است. به نظر مى رسد كه تفاوت در روش جمع اورى

اطلاعات و منابع مورد استفاده براى نمونه كيرى باعث

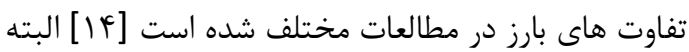
بايد توجه داشت كه در اين مطالعه بدليل تكميل يرسشنامه ها توسط روانشناسان مراكز درمان اعتياد از

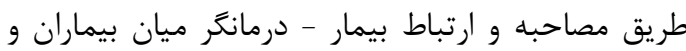

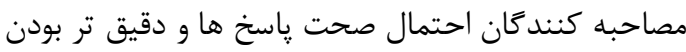
اطلاعات از ارزيابى هاى خانه به خانه و و يا تكان تكميل يرسشنامه توسط خود بيماران بيشتر است. اين مطالعه إنه

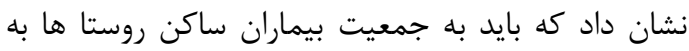
عنوان حجم بزركى از بيماران توجه بيشترى شود و در

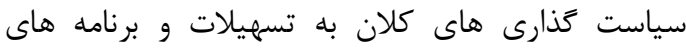

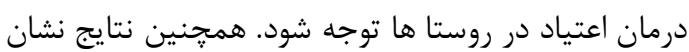
مى دهد كه تمايل به مراجعه به مراكز درمانى در ميان

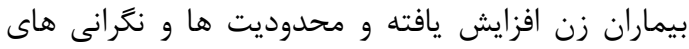
زنان براى مراجعه به منظور ترك اعتياد، حداقل در استان بان خراسان شمالى كاهش يافته است.

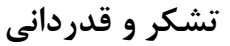
اين مطالعه با همكارى 19 مركز درمان اعتياد در خراسان

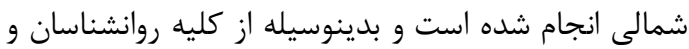

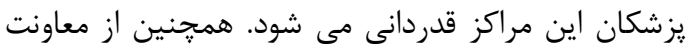

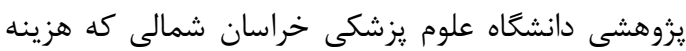
بالاى اين طرح تحقيقاتى را حمايت نمودند تشكر و قدر

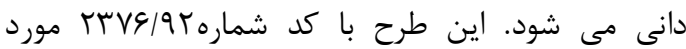

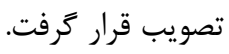

\section{References}

1.Hojjat SK HM, Addiction and Social Harms: ARVIJ PUBLICATION; 2013.

2.Bahrami Ehsan H, Addiction and process of prevention, Tehran: Samt Inc. 2004[Persian]

3.Razzaghi E, Rahimi A, Hosseini M, Chatterjee A,Rapid Situation Assessment (RSA) of drug abuse in Iran. Prevention Department, State Welfare Organization, Ministry of Health, IR of Iran and United Nations International Drug Control Program, 1999[Persian]

4.United nations office on drugs and crime .Epidemiology of drug use in iran 2007, [Home page on the internet]2007
شيوع شناسى اعتياد در شهروندان ايرانى (•9 (I ) ميزان

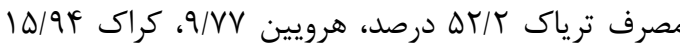

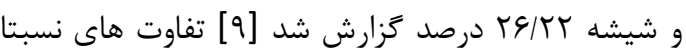
زياد در نتايج جند مطالعه اخير مى تواند به دليل تفاوت

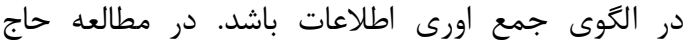

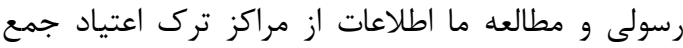

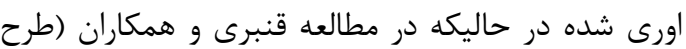
ملى شيوع شناسى) اطلاعات از طريق يرسشنامه و ارزيابى

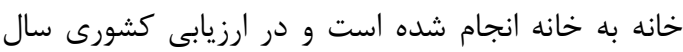

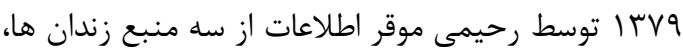

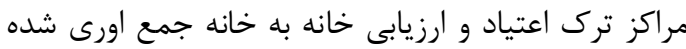

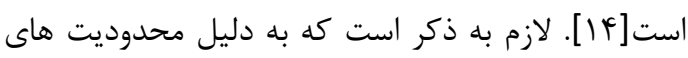

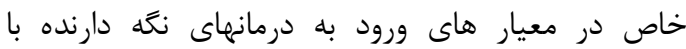

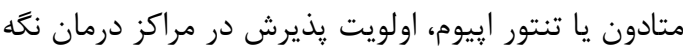

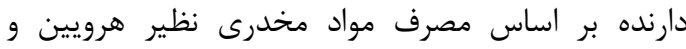
كراى يا وجود رفتارهاى ير خطر نظير مصرف همزمان

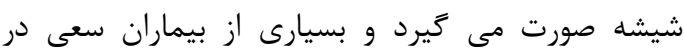

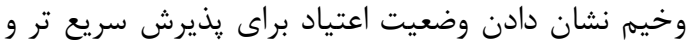

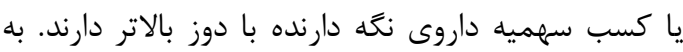
اين دلايل تفسير نتايج نوع و الكَى ماده مخدر مصرفى

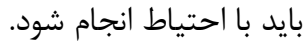
نتيجه كيرى

مقايسه نتايج اين مطالعه با نتايج مطالعات ديكر دركشور نشان دهنده تفاوت در مشخصات دموكرافيك بيماران از جمله سن و وضعيت تاهل و تحصيلات و الكَى مصرف دئن

[cited2010Feb11].Availeablefrom:www.Unodc .org/Iran/en/epidemiology.html2010.

5.Sandeep c. world drug report 2011,United nations office on drugs and crime (UNODC). 2011.

6.RAHIMI MOVAGHAR A, A review on the prevalence and the patterns of drug abuse in women in Iran. Social Welfare, 2004[Persian] 7.Jafari S, Movaghar AR, Baharlou S, Spittal $\mathrm{P}$, Craib KJ, Trends of Substance Use in Southern Iran: A qualitative study, Internet Journal of Epidemiology. 2008;6(1) [Persian] 8.Rahimi Movaghar A, Mohammad K, Razzagi E, Trend of drug abuse situation in Iran: a three-decade survey. Hakim Res J. 2002;5(3):171-81[Persian] 
9.SARRAMI H, GHORBANI M, MINOOEI $M$, Survey of four decades of addiction prevalence researches in Iran, J Res Add. 2013;7(26):29-52[Persian]

10.Kandall SR, Substance and shadow: Women and addiction in the United States: Harvard University Press; 1999.

11.Ahmadi J, Pridmore S, Alimi A, Cheraghi A, Arad A, Parsaeyan H, "et al”,Epidemiology of opium use in the general population, The American journal of drug and alcohol abuse, 2007;33(3):483-91.
12.Abbasi A, Tzatziki S, Moradi A, The prototype of drug mis.abused of opioids in the self-introduced addicts in Gorgan (North-East of Iran), J Gorgan Uni Med Sci. 2006;8(1):227.

13.Daneshmandan N, Narenjiha H, Tehrani K, Assari S, Khoddami-Vishteh H-R. Initiation to the first drug use among substance-dependent persons in Iran, Substance use \& misuse, 2011;46(9):1124-41[Persian]

14.Moghanibashi-Mansourieh A, Deilamizade A, The state of data collection on addiction in Iran. Addiction. 2014;109(5):854-[Persian] 
Original Article

\title{
Social, economical and population characteristics of substance dependents treated in North khorasan drug rehabilitation centers
}

\author{
Norouzi khalili $M^{1}$, Hojjat $S K^{2}$, Khajedaluee $M^{3^{*}}$, Erfanian $M^{4}$, Akaberi $A^{5}$ \\ ${ }^{1}$ Assistant of Community Medicine .Department of Community Medicine, Mashhad University of Medical \\ Sciences.mashhad.Iran. North Khorasan University of medical sciences. Addiction and Behavioral Sciences \\ Research Center, \\ ${ }^{2}$ Assistant professor of psychiatry, Addiction and Behavioral Sciences Research Center. North Khorasan \\ University of medical sciences. Bojnurd.Iran \\ ${ }^{3 *}$ Associate Professor of Community Medicine .Department of Community Medicine, Mashhad University of \\ Medical Sciences.mashhad.Iran \\ ${ }^{4}$ Associate Professor of infectious diseases .Department of Community Medicine, Mashhad University of \\ Medical Sciences.mashhad.Iran \\ ${ }^{5} \mathrm{MSC}$ of Biostatics, Addiction and Behavioral Sciences Research Center. North Khorasan University of medical \\ sciences. Bojnurd.Iran
}

$\begin{array}{lr}\text { *Corresponding } & \text { Author: } \\ \text { Department of } & \text { Community } \\ \text { Medicine,School } & \text { of } \\ \text { Medicine,Mashhad } & \text { University } \\ \text { of } & \text { medical }\end{array}$

Sciences.mashhad.Iran.

Email:KhajedalueeM@mums.a c.ir

Submitted:22 Apr 2014

Revised:7 May 2014

Accepted: 26 May 2014

\begin{abstract}
Background \& Objectives: Substance abuse is one of the four crisis threatening humanity with the environmental, nuclear and population. Iran is among the countries due to the proximity of Afghanistan, the world's largest producer of opium and heroin extremely affected by substance dependency issue. Currently, there are about 2 million drug dependents living in Iran and this is a major health and social priority.
\end{abstract}

Material \& Methods: this research is a cross sectional study in $2012-2013$ on substance dependent patients treated in methadone maintenance clinics. Subjects assessed by clinical psychologists interviewing and a checklist include demographic characteristic, social, economical and pattern of abuse. We used Chi square for comparison of qualities' variables between gender and T Student and mann whitney test for quantitive variables. Data were analyzed with spss 11.5 software.

Results: in this study 7342 patients who treated in methadone maintenance clinics were assessed. $82.5 \%$ male and $17.5 \%$ were female. $87.5 \%$ of all subjects were married.6.6\% single and $5.9 \%$ were divorced.95\% of patients had history of opium dependency and $14 \%$ had history of heroin and crack and $2.8 \%$ had history of codependency with methamphetamine.

Conclusion: our results showed significant differences between demographic characteristic of patients under maintenance treatment and other groups of addicts especially in mean age and male/female ratio.

Key words: demographical characteristics, substance dependency, drug rehabilitation centers 